\title{
Wind Tunnel Tests for Mean Wind Loads on Road Vehicles
}

\author{
Xianzhi Liu ${ }^{1}$, Yan $\mathrm{Han}^{2 *}$, C. S. Cai ${ }^{{ }^{*}}$, Marc Levitan ${ }^{3}$ and Dimitris Nikitopoulos ${ }^{4}$ \\ ${ }^{1}$ Dept. of Civil and Environmental Engineering, Louisiana State University, Baton Rouge, Louisiana, USA, LA 70803 \\ ${ }^{2}$ School of Civil Engineering and Architecture, Changsha University of Science \& Technology, Changsha, China, \\ 410004 \\ ${ }^{3}$ Formerly Dept. of Civil and Environmental Engineering, Louisiana State University, Baton Rouge, Louisiana, USA, \\ LA 70803 \\ ${ }^{4}$ Dept. of Mechanical Engineering, Louisiana State University, Baton Rouge, Louisiana, USA, LA 70803
}

\begin{abstract}
Evaluation of the safety and performance of road vehicles in windy conditions requires accurate descriptions of wind loads on vehicles. However, the research in this area has been far from comprehensive. In the present study, wind tunnel tests were carried out on various vehicle models under different flow conditions, including smooth flow, turbulent flow, and boundary layer flow. The lift, drag, and side forces, and the pitching, rolling, and yawing moments for these vehicle models were measured and analyzed to interpret the effects of flow conditions on these forces. The results were also compared with other wind tunnel tests results published in the literature. The experimental results reveal that the flow conditions did have effects on the variation of wind loads; the smooth flow case is a conservative estimation in general. The height of the center of gravity of the vehicle will significantly affect the results of the aerodynamic moment coefficients, which causes the significant difference between different studies. The results under the boundary layer flow also provide a good reference guide for the context of applications such as stability problem of still vehicles under extreme wind events.
\end{abstract}

Keywords: Wind tunnel test; wind loads; road vehicles; smooth flow; turbulent flow; boundary layer flow.

\section{Introduction}

Economic and social developments result in a tremendous increase of the traffic volume over roads and bridges. In the scenario of land falling hurricanes or severe local storms, strong winds may pose threats to the safety of the motorists and vehicles on the road or the bridge. A large number of wind-induced accidents have been reported all around the world (Baker and Reynolds 1992). In order to evaluate the accident risk and stability for road vehicles under wind actions,

\footnotetext{
${ }^{a}$ Corresponding Author, e-mail: ce_hanyan@163.com; cscai@1su.edu
} 
the aerodynamic load is among the essential information needed to carry out the evaluation. Various approaches can be adopted to evaluate the wind loads on vehicles. Due to the difficulties in computational fluid dynamics and the expense involved in full-scale measurements, a wind tunnel study is probably the most convenient and reliable approach to investigate this problem.

Data of aerodynamic loads on a double deck bus provided by Garry (1984) were quoted by Baker (1986), who performed wind tunnel tests with a 1/12-scaled model of a Leyland Altantaean bus. It was noted that the effects of atmospheric turbulence and model/ground relative motion were not modeled for the tests, and the accuracy of these results were in doubt. In order to assess the effect of high winds on traffic in general, several standard types of vehicles were defined in a later study by Baker (1987), including cars, coaches, large rigid vans, and articulated tractor-trailers. In both of the above studies, the six aerodynamic coefficients were given in a simplified formula format. While comparisons of the Large Van category and Leyland Altantean Bus category in these two different studies show that they have very similar geometric parameters, the aerodynamic loads have significant difference. There are insufficient further details given in these reports that may be held accountable for this difference. In order to study the behavior of high-side vehicles in cross wind, Baker (1988) carried out a wind tunnel study on a 1/25 scale articulated-lorry model, using a low turbulence flow and a static setup (neither moving ground nor atmospheric turbulence effect were simulated). The test results for the aerodynamic force coefficients were fitted with simple analytical curves. The comparison of this formulation to the earlier mentioned study (Baker 1987) show close values and similar trends in some cases, but also significant difference of magnitudes in other cases. Coleman and Baker (1990) measured the load coefficients of an articulated lorry positioned on the bridge deck model. Their studies showed that the effect of turbulence on the aerodynamic properties of the vehicle was significant. Furthermore, Coleman and Baker (1994) carried out wind tunnel tests to measure the mean and fluctuating values of the aerodynamic force coefficients and surface pressure coefficients on a 1/50 scale articulated lorry model on a bridge deck and revealed the flow mechanisms involved.

The review of all the previous studies reveals that a scheme of reliable estimation of aerodynamic loads on road vehicles is still far from established. This is due to the complicated nature of the problem related to scaling rules, flow simulation, the effects of local topography and infrastructure, as well as the limitations of wind tunnel technology. This situation will be 
more complicated when considering vehicles operated on long span bridges due to the interaction between the vehicles and bridge. Chen and Cai (2004); Guo and Xu (2006) demonstrated that for the same wind velocity the risk of vehicle instability is higher if a vehicle is crossing a long span bridge as opposed to travelling on a road. For extending the existing data, Dorigatti et al. (2012) investigated the aerodynamic properties of high sided vehicles over long span bridges by carrying out a series of wind tunnel experiments to measure the aerodynamic forces of three 1:40 scale model vehicles placed on the bridge: a Van, a Bus and a Lorry. Zhu et al. (2012) measured aerodynamic coefficients of four types of road vehicles over a typical bridge deck in low turbulence fields in wind tunnel and investigated the effects of the bridge deck on aerodynamic coefficients. Han et al. $(2011 ; 2013)$ investigated the aerodynamic characteristics of road vehicles on a bridge by using the CFD method and by carrying out a series of wind tunnel tests considering the interaction of the aerodynamic forces between the road vehicles and the bridge. In their studies, only one type of vehicles is included and the vehicle is simplified for the measurement of pressure distributions.

As responders to the accident, emergency vehicles, such as fire trucks and ambulances, are desired to continue to operate provided that their own safety is not compromised. One of the motivations for this study is the concern over the safety of the emergency vehicles and other high-side vehicles under strong wind conditions on long span bridges. Some studies (Cai and Chen 2004; Chen and Cai 2004; Xu and Guo 2003; Li et al. 2005; Han and Chen 2007) have made good progress on setting up feasible framework to numerically study the performance of vehicles under wind actions on long span bridges. The success of these analytical approaches no doubt relies upon an accurate description of the aerodynamic loads on the corresponding vehicles. Since aerodynamic force data on emergency vehicles is scarce, and the information on the vehicle geometry and dimensions are often missing, even if some wind tunnel test data are available, making reference to these data inherently causes large uncertainties. In this study, a wind tunnel study was conducted to fill this void and provide necessary information for analytical work.

Section 2 gives the definition of force coefficients for wind loads on vehicles. Section 3 describes the experimental apparatus and measurement techniques. The experimental results and discussions are presented in Section 4. Finally, some conclusions are drawn in Section 5. It is found that the flow conditions did have effects on the variation of wind loads; the smooth flow 
case is a conservative estimation in general. The height of the center of gravity of the vehicle will significantly affect the results of the aerodynamic moment coefficients, which causes the significant difference between different studies. The results under the boundary layer flow also provide a good reference guide for the context of applications such as stability problem of still vehicles under extreme wind events.

\section{Definition of force coefficients for wind loads on vehicles}

A coordinate system with the $x, y$, and $z$ axes as shown in Fig. 1 is adopted for the definition of the aerodynamic forces and moments, following the most frequently used convention. The mean aerodynamic drag force $(D)$, side force $(S)$, and lift force $(L)$ are in the positive $x, y$, and $z$ directions, respectively, acting at the center of gravity (CG). The mean aerodynamic rolling moment $\left(M_{R}\right)$, pitching moment $\left(M_{P}\right)$, and yawing moment $\left(M_{Y}\right)$ follow the right-hand screw rule about the $x, y$, and $z$ axes, respectively. All the mean force coefficients are referred to the frontal area of the vehicle, and the moment coefficients are referred to the frontal area times the height of the CG from the ground, $h_{v}$. Mean aerodynamic force and moments coefficients are then defined as:

$$
\begin{gathered}
C_{S}(\psi)=S / 0.5 \rho V^{2} A \\
C_{L}(\psi)=L / 0.5 \rho V^{2} A \\
C_{D}(\psi)=D / 0.5 \rho V^{2} A \\
C_{P}(\psi)=P / 0.5 \rho V^{2} A h_{v} \\
C_{Y}(\psi)=Y / 0.5 \rho V^{2} A h_{v} \\
C_{R}(\psi)=R / 0.5 \rho V^{2} A h_{v}
\end{gathered}
$$

where $S, L, D, P, Y$, and $R$ are the mean side force, lift force, drag force, pitching moment, yawing moment, and rolling moment, with their sign conventions shown in Fig. 1, which are measured by the force balance and averaged over the required time period of $60 \mathrm{~s}$; $C_{S}(\psi), C_{L}(\psi), C_{D}(\psi), C_{P}(\psi), C_{Y}(\psi)$ and $C_{R}(\psi)$ are their corresponding coefficients; $\psi$ is the 
yaw angle, which can be produced by changing the vehicle speed or changing the wind angle $\beta$ by rotating the vehicle, as shown in Fig. 2 , if no vehicle movement is considered; $A$ is the frontal area of the vehicle; $h_{v}$ is the distance from the gravity center of the vehicle to the road surface; and $V$ is the relative wind speed to the vehicle as shown in Fig. 2. Meanwhile, in Fig. 2, $U$ is wind velocity, $v$ is the vehicle speed, $\beta$ is the wind angle between the wind direction and the vehicle direction of travel, and $\beta=\psi$ and $V=U$ in this study since no vehicle movement is considered.

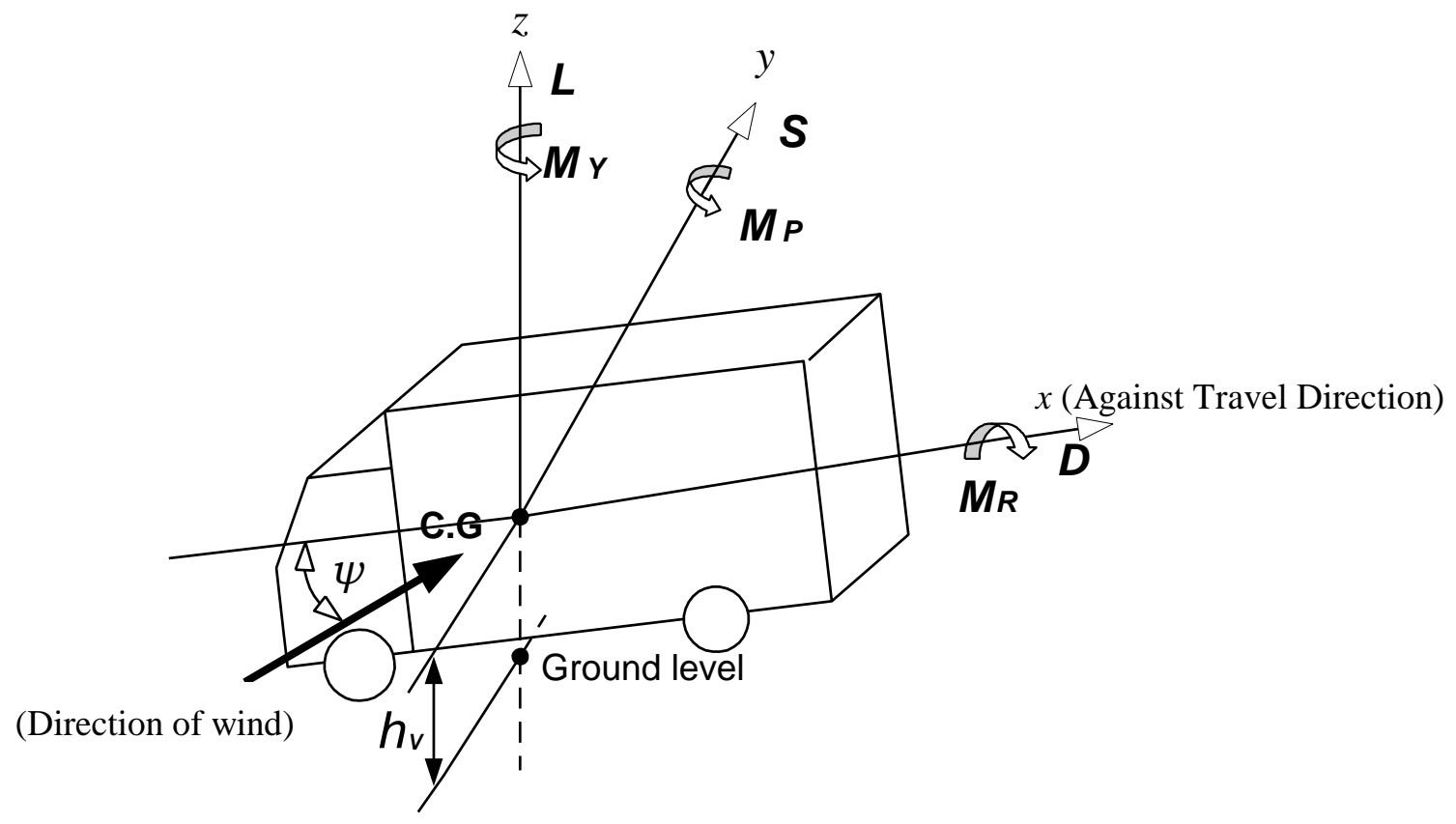

Fig. 1 Sign conventions for aerodynamic forces of the vehicle

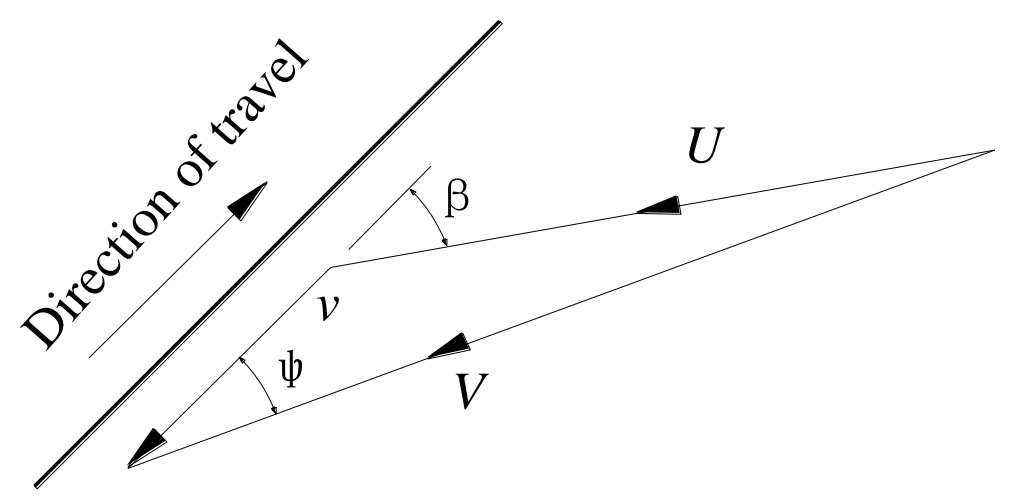

Fig. 2 Velocities and directions 


\section{Experimental setup}

Scaled models were tested in the wind tunnel laboratory at Louisiana State University. The wind tunnel has a test section of $0.99 \mathrm{~m}$ height and $1.32 \mathrm{~m}$ width with a maximum velocity of 15 $\mathrm{m} / \mathrm{s}$ approximately. The vehicle models were mounted on a turntable, which was attached to a six-component sting balance as shown in Fig. 3. The balance presents different design loads associated to the different components of the forces and moments. The design loads corresponding to the side and drag forces, the lift force, and the three torques are $80 \mathrm{~N}, 240 \mathrm{~N}$ and $4 \mathrm{~N}$. $\mathrm{m}$, and the corresponding resolutions are 1/50,1/25, and 1/2000, respectively. The accuracies can be estimated as $1.2 \%$. The turntable was $0.304 \mathrm{~m}$ in diameter. It can be rotated $0 \sim 360$ o together with the sting balance. To reduce the boundary layer effects (in which the wind tunnel boundary layer is usually much thicker than the actual one), the turntable was elevated $0.152 \mathrm{~m}$ from the bottom of wind tunnel test section. A platform with dimensions of $0.91 \mathrm{~m}$ by $1.22 \mathrm{~m}$ was built at the same height of the turntable to simulate the ground/road condition and provide a more uniform flow field around the vehicle model. The leading edge of the platform was sharpened to provide a smooth initiation of a boundary layer, as shown in Fig. 3. Fig. 4 shows a picture of a typical turbulent flow test set up, with the turbulence-generating grid installed in the upstream location and the fire truck model mounted on the platform. The distance between the turbulence grid and the center of the test section (where the model was mounted to the force balance) is $155 \mathrm{~cm}$. This location was selected, after tried at different locations, as it can induce relatively high turbulence intensity.

Three types of flow conditions, i.e., the smooth, turbulent, and boundary layer flows, were simulated for the tests. The smooth flow and turbulent flow generated by a grid screen were adopted for the platform setup. The flow conditions, such as the mean velocity, turbulence intensity, and turbulence length scale was obtained based on the velocity time history that was measured and characterized with a hotwire system. For the smooth flow condition, the turbulence intensities were less than $1 \%$ for all heights greater than $3 \mathrm{~cm}$ and the velocities were relatively constant in this range. The turbulence intensity for the turbulent flow ranged between $4.75 \%$ and $5.5 \%$ for all heights greater than $3 \mathrm{~cm}$. The longitudinal length scale of the grid turbulence was approximately $5.5 \mathrm{~cm}$. The third flow condition was the atmospheric boundary layer flow with the vehicle models sitting directly on the wind tunnel floor. The grid and trips had been deployed 
to generate a boundary flow condition. The velocity and turbulent intensity profile were shown in Fig. 5. Fig. 5 also included a best-fit power law approximation of the velocity profile and a reference profile for the turbulence intensity. The roughness length, $Z_{0}$, selected for this turbulence intensity reference calculation was $0.003 \mathrm{~m}$, which corresponds to the suburban terrain at a scale of 1:32. The surface roughness length was estimated based on the best-fit of the measured boundary-layer profile. Fig. 6 shows a picture of the typical setup with a tractor-trailer model mounted and ready for the boundary layer flow test.

Four types of vehicle models were studied including the tractor-trailer, fire truck, pickup truck, and sedan types. The geometries and dimensions are presented in Figs. 7-10. The heights of their gravity centers from the bridge deck surface or the ground $\left(h_{v}\right)$ are $35.6 \mathrm{~mm}, 44.0 \mathrm{~mm}$, $57.1 \mathrm{~mm}$, and $46.9 \mathrm{~mm}$, respectively. A test matrix of all the tested configurations is given in Table 1. The blockage ratios based on the frontal area and side area for each vehicle model are also presented in the table. As can be seen, the blockage ratios are well below the commonly believed limit value of $7.5 \%$ (Katz 2006). Therefore, the effects due to blockage were expected to be negligible and no corrections were applied for this purpose.

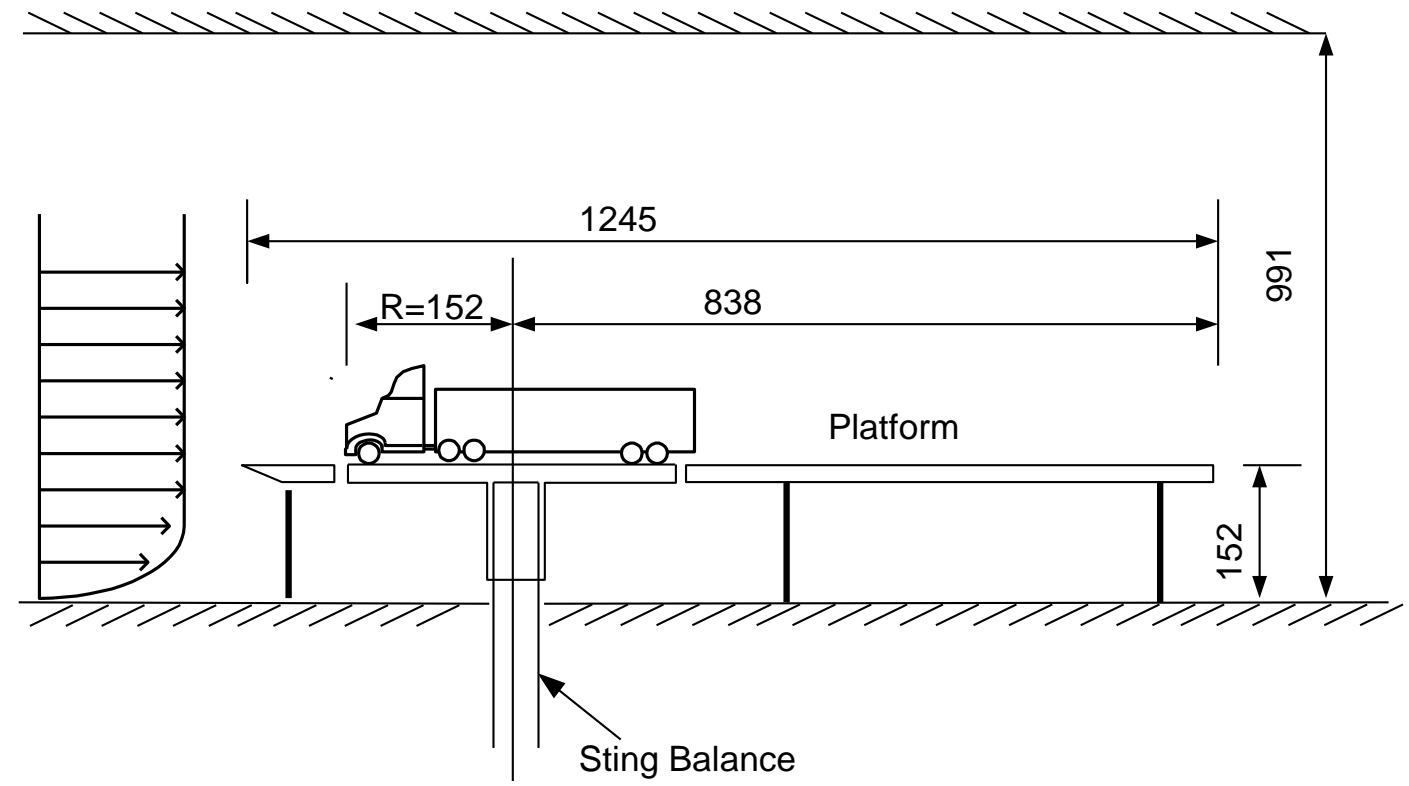

Fig. 3 Schematic setup for wind tunnel test on vehicle models (unit: mm) 


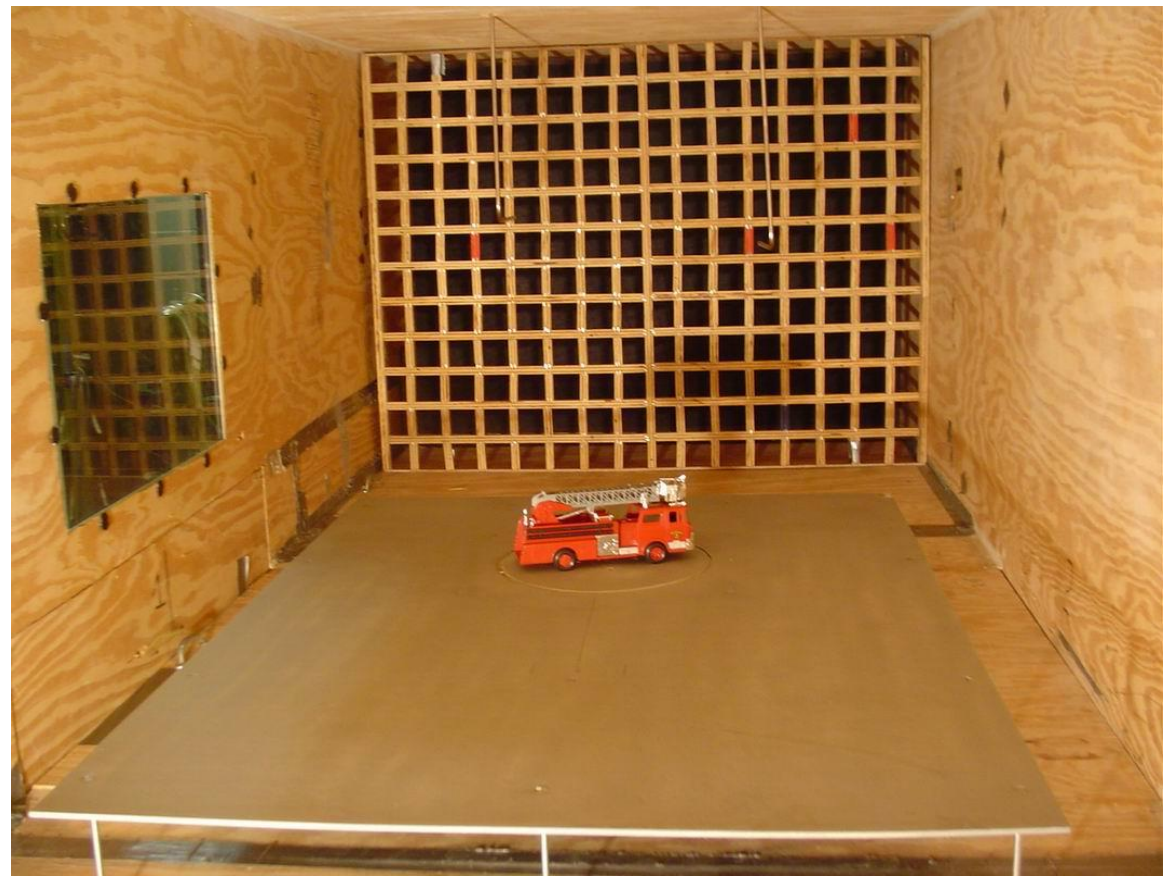

Fig. 4 Testing of fire truck model in turbulence flow condition

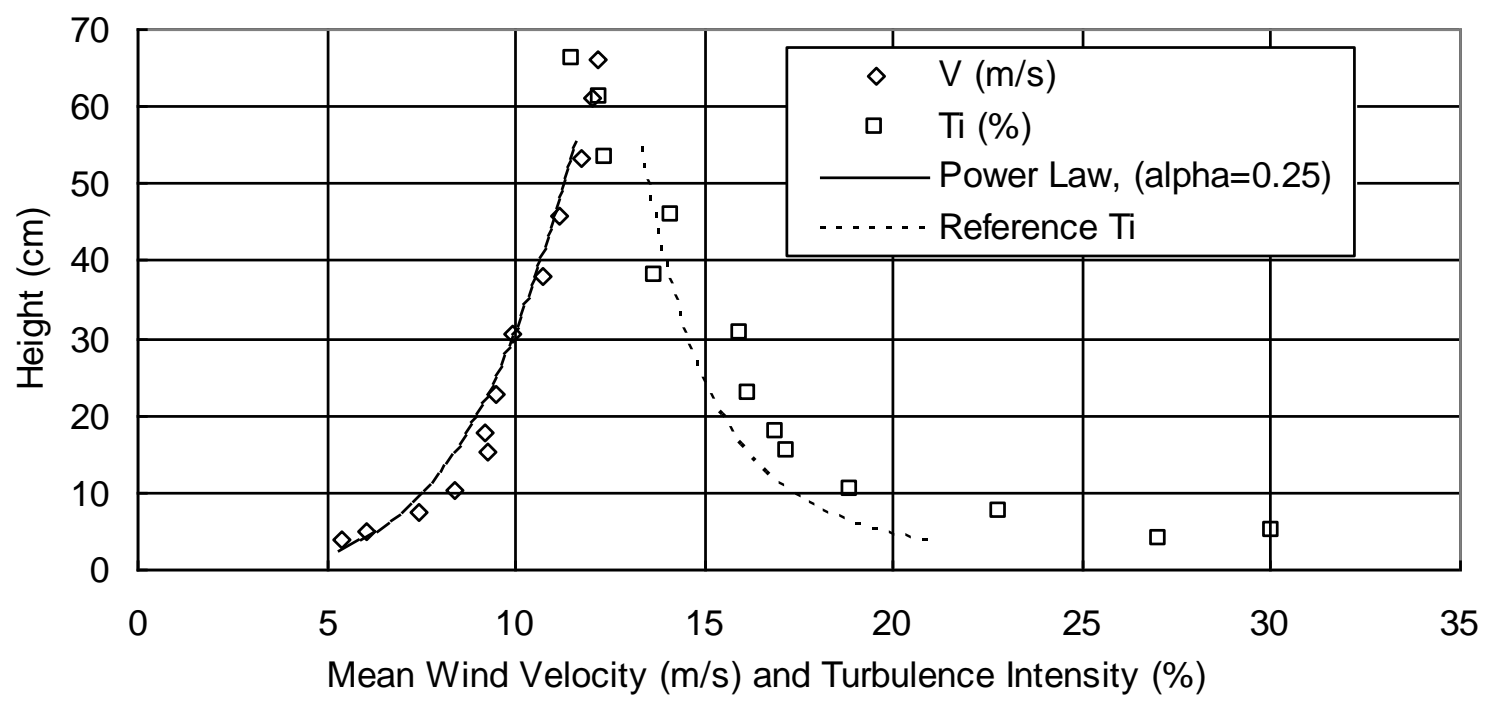

Fig. 5 Velocity and turbulent intensity profile for boundary layer flow 


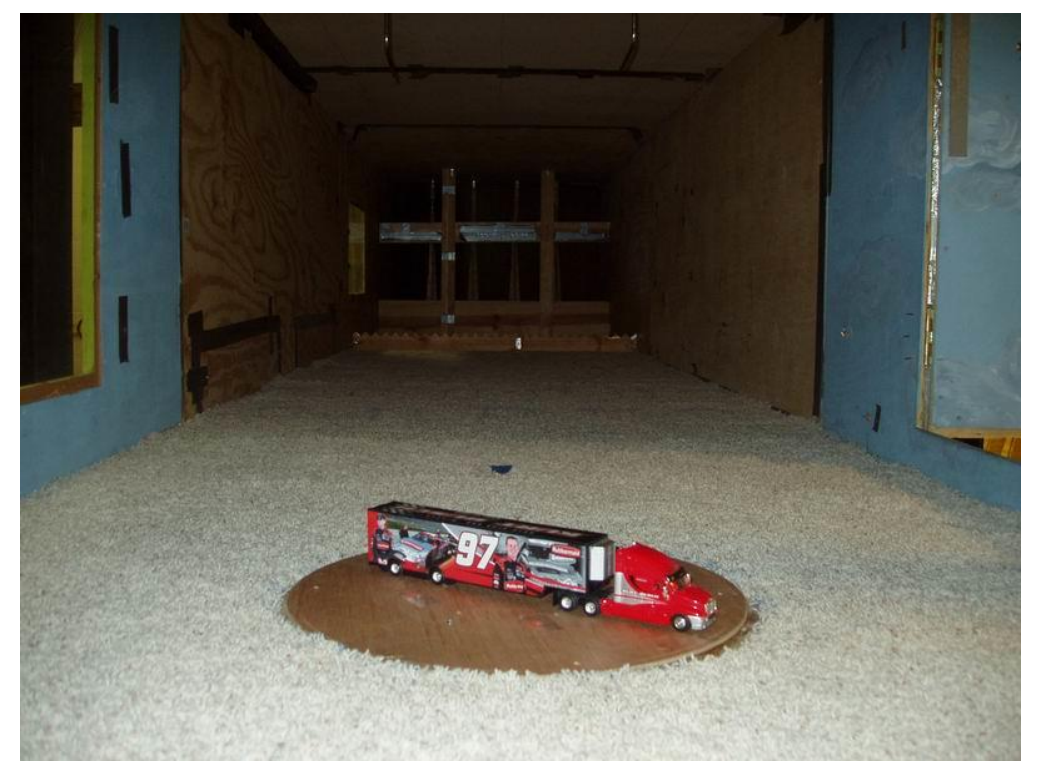

Fig. 6 Testing of tractor-trailer model in boundary layer flow condition

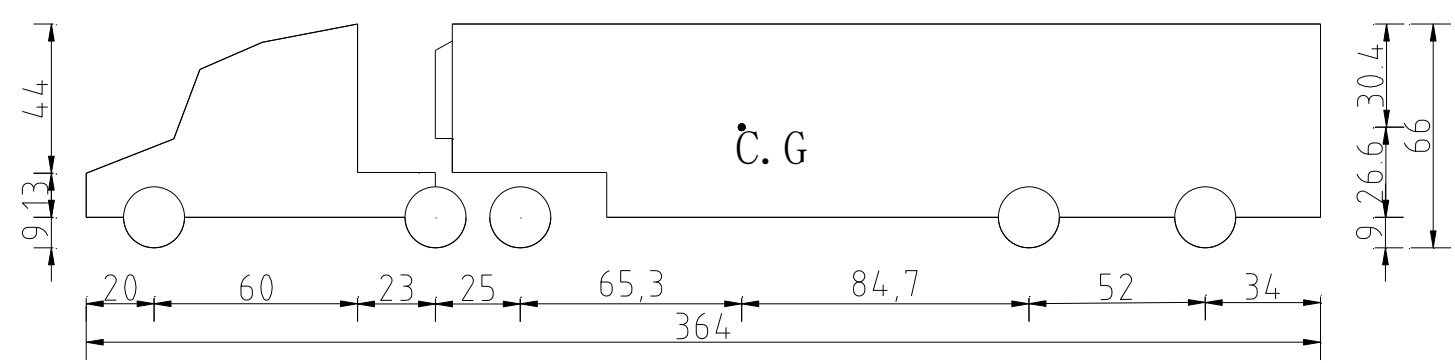

Fig. 7 Geometry and dimensions of tractor-trailer model (unit: mm)

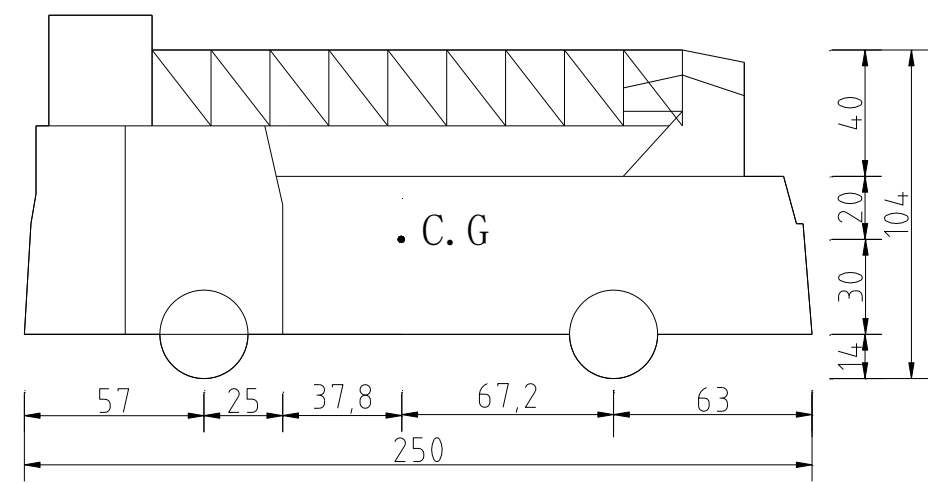

Fig. 8 Geometry and dimensions of fire truck model (unit: mm) 


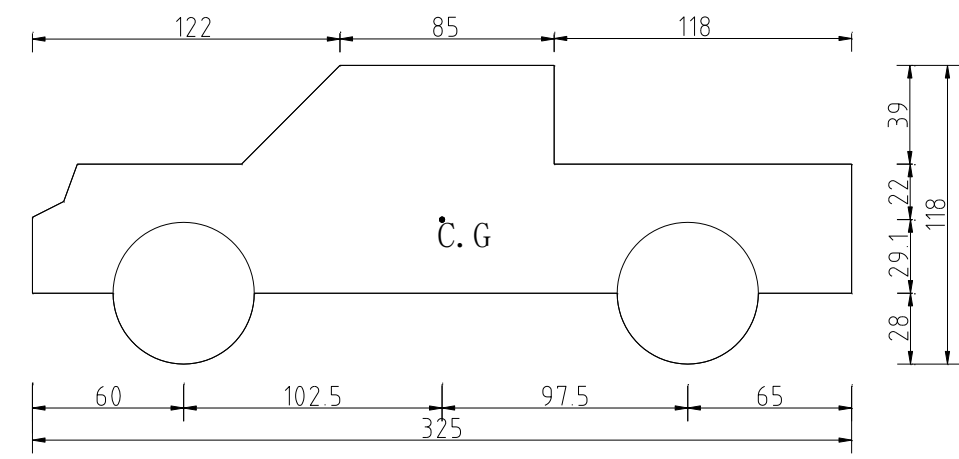

Fig. 9 Geometry and dimensions of the pickup truck model (unit: mm)

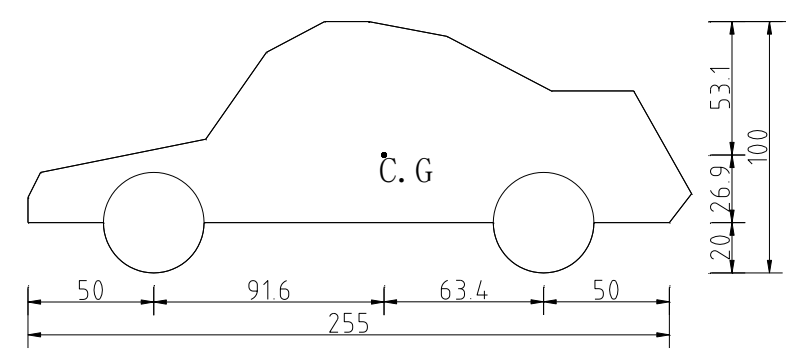

Fig. 10 Geometry and dimensions of the sedan model (unit: mm)

Table 1 Test matrix for different vehicle models and flow conditions

\begin{tabular}{|c|c|c|c|c|c|}
\hline \multirow{2}{*}{$\begin{array}{c}\text { Vehicle } \\
\text { models }\end{array}$} & \multicolumn{3}{|c|}{ Flow Condition } & \multirow{2}{*}{$\begin{array}{c}\text { Blockage Ratio } \\
(\%)\end{array}$} & $\begin{array}{c}\text { Blockage Ratio } \\
(\%)\end{array}$ \\
\cline { 2 - 4 } & Flow & $\begin{array}{l}\text { Turbulent } \\
\text { Flow }\end{array}$ & $\begin{array}{l}\text { Boundary } \\
\text { Layer Flow }\end{array}$ & 0.2 & 1.8 \\
\hline Tractor-trailer & $*$ & $*$ & $*$ & 0.5 & 2 \\
\hline Fire Truck & $*$ & $*$ & $*$ & 1 & 2.9 \\
\hline Pickup truck & N.A. & N.A. & $*$ & 0.8 & 1.9 \\
\hline Sedan & N.A. & N.A. & $*$ & \\
\hline
\end{tabular}

Note: $*=$ Tested; N.A. $=$ not tested

\section{Results and discussions}

\subsection{Tests in smooth flow condition}

Since most of the available data in the literature was obtained in smooth flow condition, for the convenience of comparisons, tests were performed in smooth flow as well in this study. The tractor-trailer model and the fire truck model were tested. The aerodynamic coefficients are presented in Figs. 11 14. To compare the current tests with other published data, the sign convention and the coordinate system are modified, as needed, to be the same as defined earlier (Section 2). 
The current tractor-trailer model results are compared with Baker's tractor-trailer type (Baker, 1987). However, the tractor-trailer model tested in this study might be significantly different from the one used in Baker's study. Based on the available information of the axle distance, it is a reasonable judgment that the model in the current study is much longer than that used in Baker's study, while the frontal areas are about the same.

From the comparison, it can be seen that the coefficients $C_{S}, C_{D}, C_{R}$, and $C_{Y}$ have similar trends, though the current study yields high values for all of them. A significant difference can also be seen for $C_{L}$ and $C_{P}$ at some angle ranges. This could be due to the longer model body used in the current study. Meanwhile, the experimental environments are not the same as those in Baker's study entirely, which may also cause the difference between them. This difference, along with other significant differences of results among different studies reported in the literature as discussed earlier, indicates that the results are sensitive to the vehicle configurations and test conditions. Further studies are needed to resolve such an issue.

Since there are no other data available for the fire truck model, the results are compared to the coach type vehicle in Baker's study (Baker, 1987), which represents the closest geometry to the fire truck. It can be seen that all the coefficients but $C_{P}$ and $C_{Y}$ show similar trends and close values in some cases. Besides, the geometry difference will cause different aerodynamic force; the values of $C_{R}, C_{Y}$ and $C_{P}$ are also very sensitive to the location of the center of gravity, based on which all the moments are defined.

Tractor-trailer in smooth flow

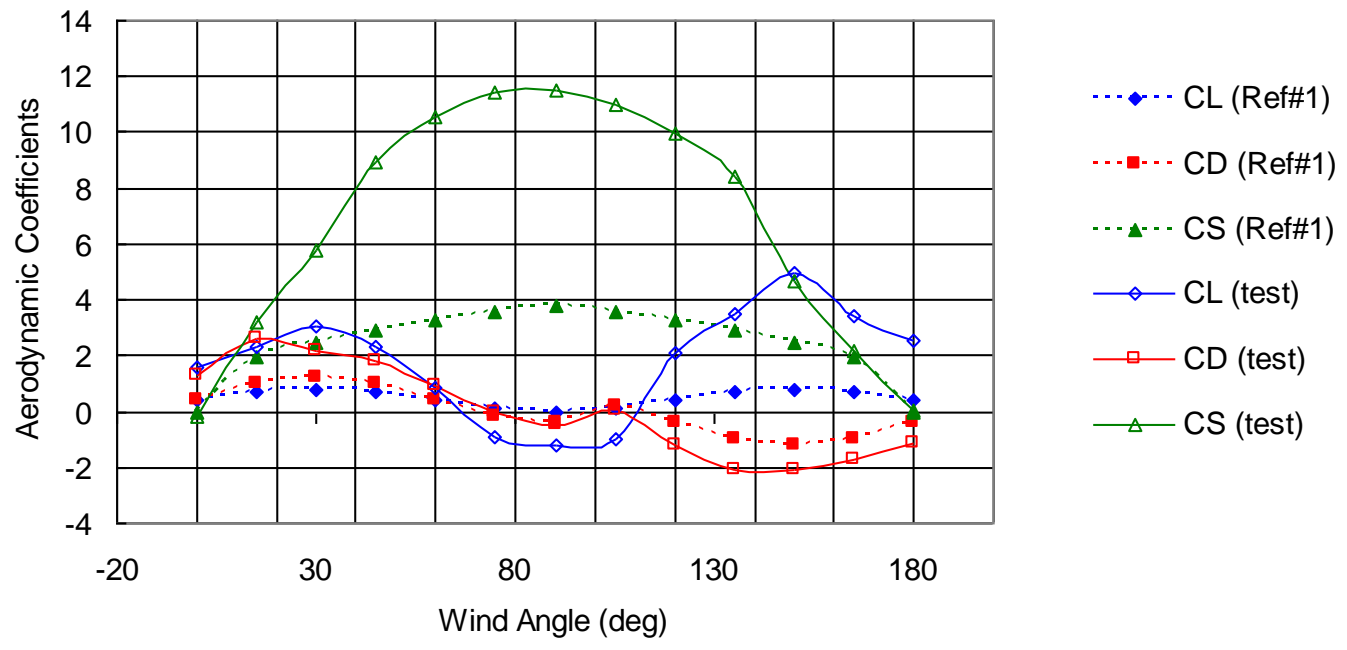

Fig. $11 C_{D}, C_{L}$ and $C_{S}$ for tractor-trailer in smooth flow (Ref\#1-Baker, 1987, tractor-trailer type) 
Tractor-trailer in smooth flow

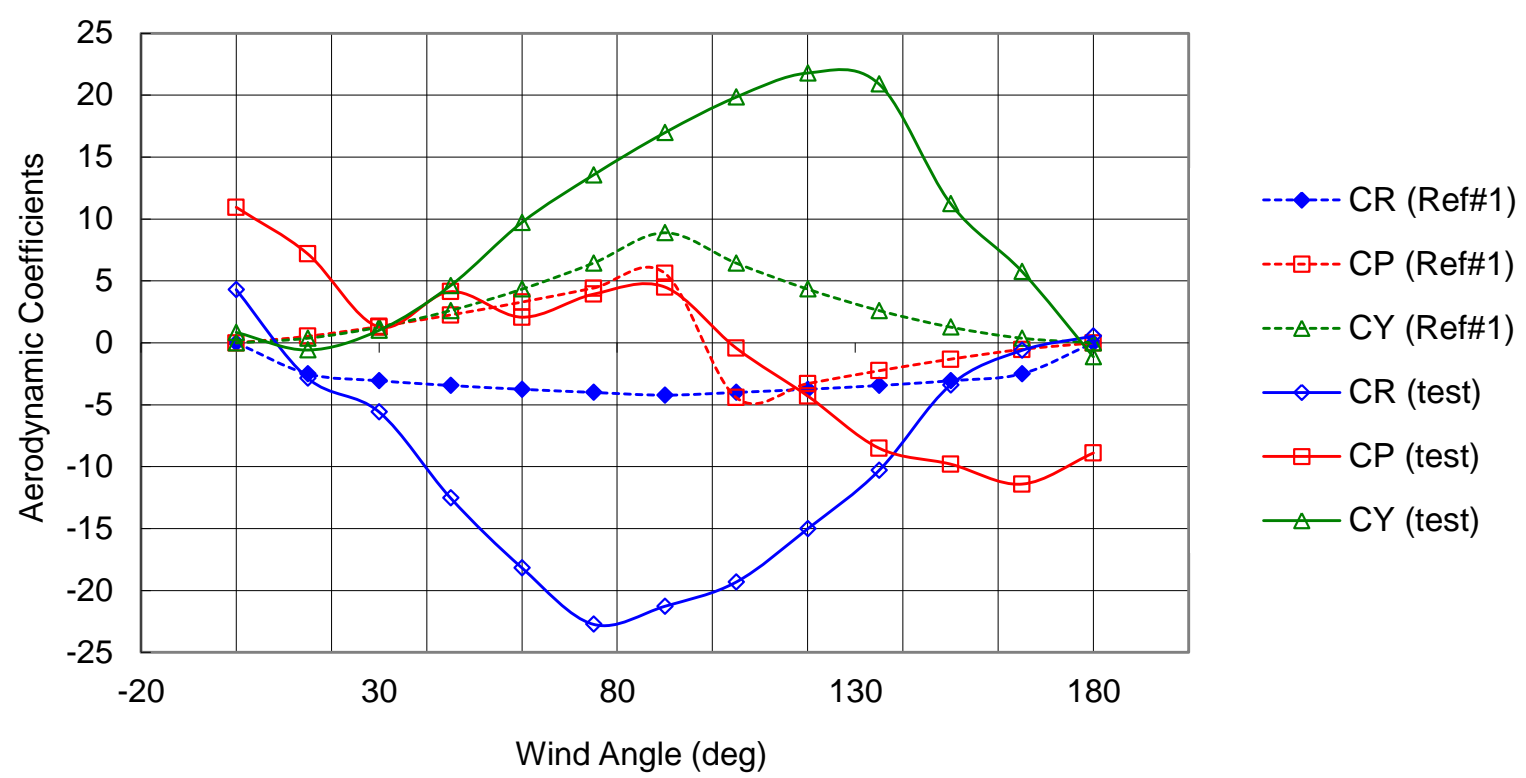

Fig. $12 C_{R}, C_{P}$ and $C_{Y}$ for tractor-trailer in smooth flow

(Ref\#1-Baker, 1987, tractor-trailer type)

Fire truck in smooth flow

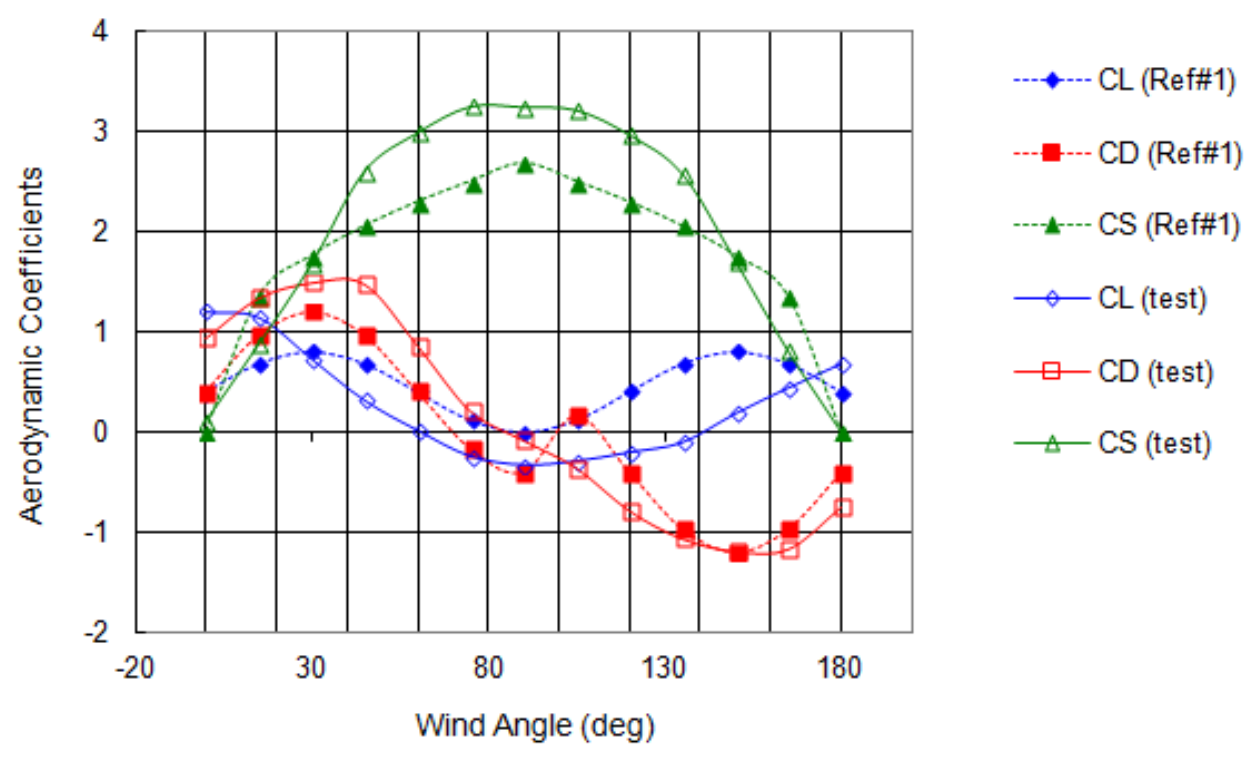

Fig. $13 C_{D}, C_{L}$ and $C_{S}$ for fire truck in smooth flow

((Ref\#1-Baker, 1987, coach type) 
Fire truck in smooth flow

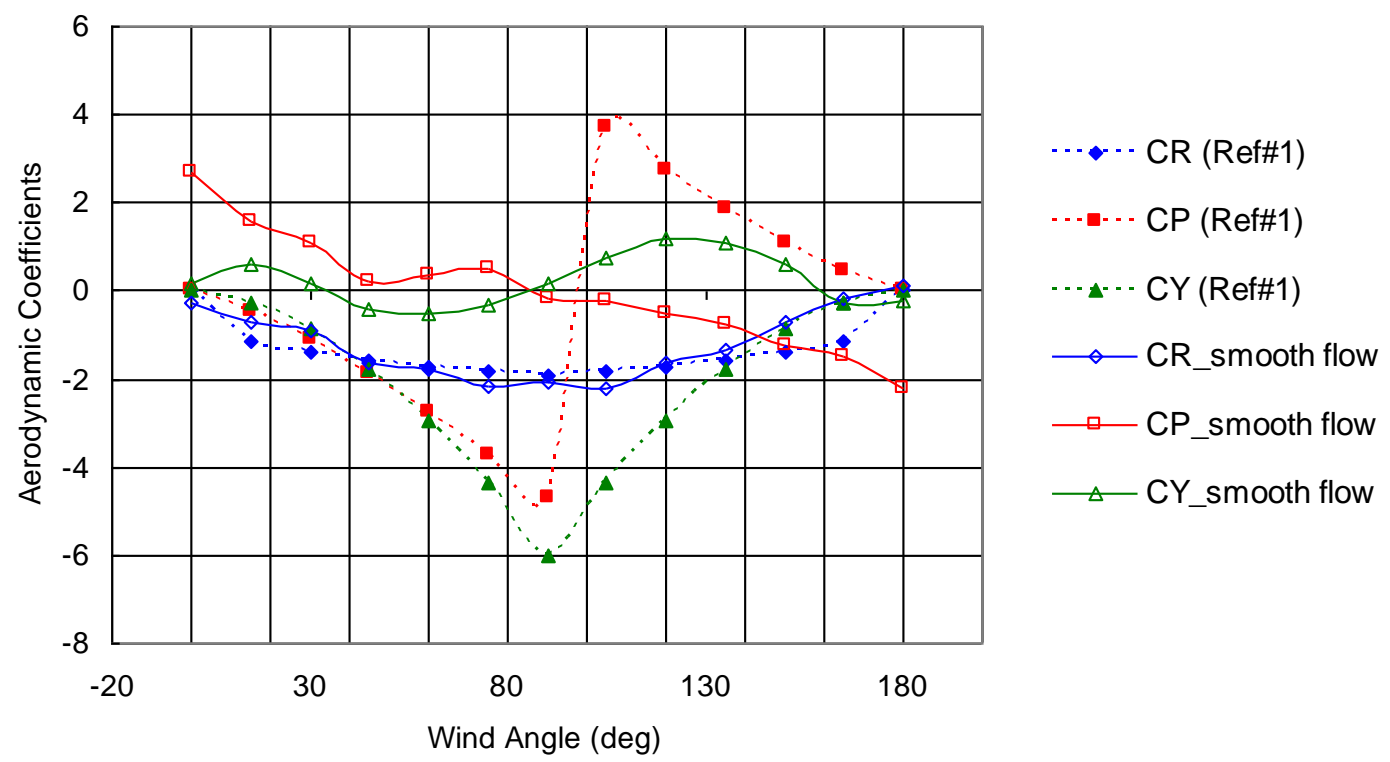

Fig. $14 C_{R}, C_{P}$ and $C_{Y}$ for fire truck in smooth flow

(Ref\#1-Baker, 1987, coach type)

Another available data set that is on a comparable basis with the fire truck results is the cargo truck, tested and reported by Han et al. (2013). The vehicle was fixed on the bridge for considering the aerodynamic interaction between the vehicle and bridge. The scale of the models was 1:32 with the details and dimensions of the models being given in Figs. 15a and 15b. The vehicle model was simplified for the measurement of pressure distributions. Comparisons of the fire truck in the smooth flow to the cargo truck, only for the range of $0^{\circ} \sim 90^{\circ}$ due to the limitation of the angle range in Han's study (Han et al., 2013), are presented in Figs. 16 and 17. A very similar trend is found for the coefficients of the aerodynamic forces, but a significant difference can be seen for the coefficients of the aerodynamic moments. Such a significant difference is probably due to the difference in the vehicle configurations and the aerodynamic interaction between the vehicle and bridge might also have contributed to this difference. 


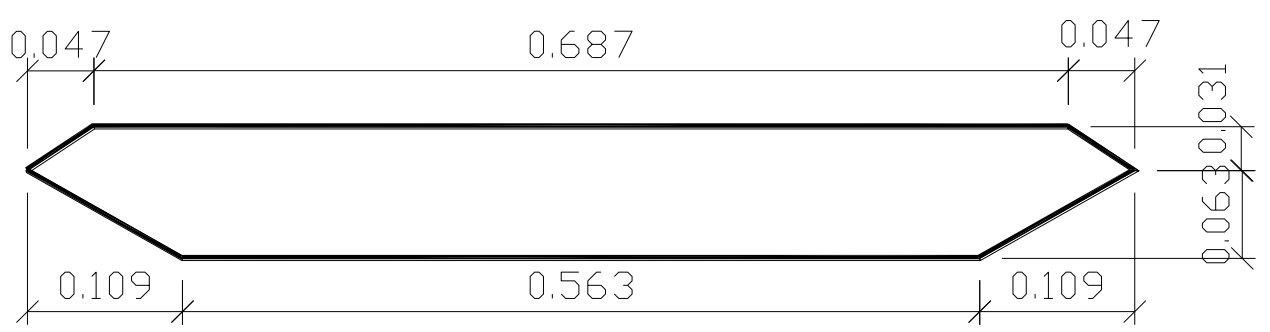

(a) Bridge cross section model

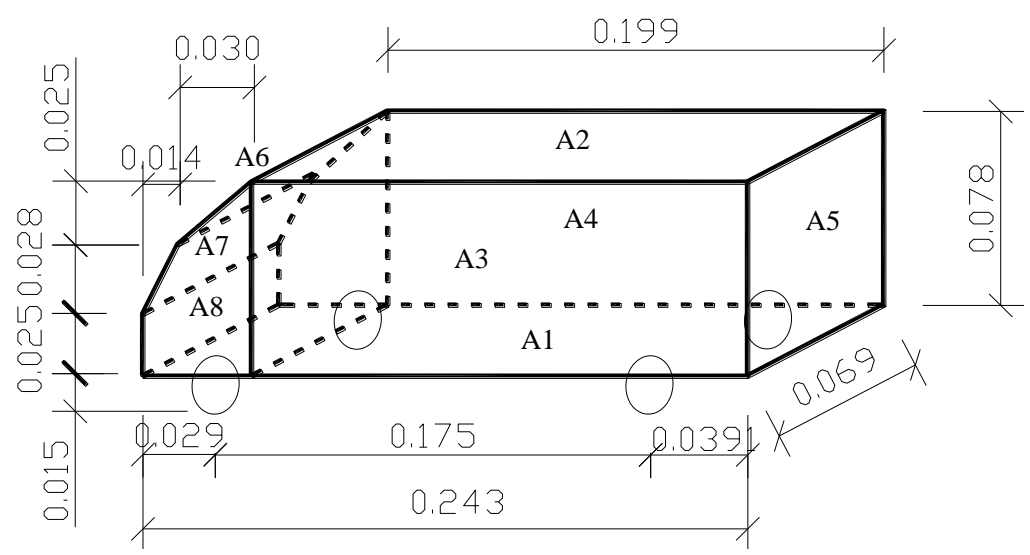

(b) Vehicle model

Fig. 15 Geometry and dimensions for Cargo truck on the bridge tested by Han (2013) (Unit:

$\mathrm{m})$
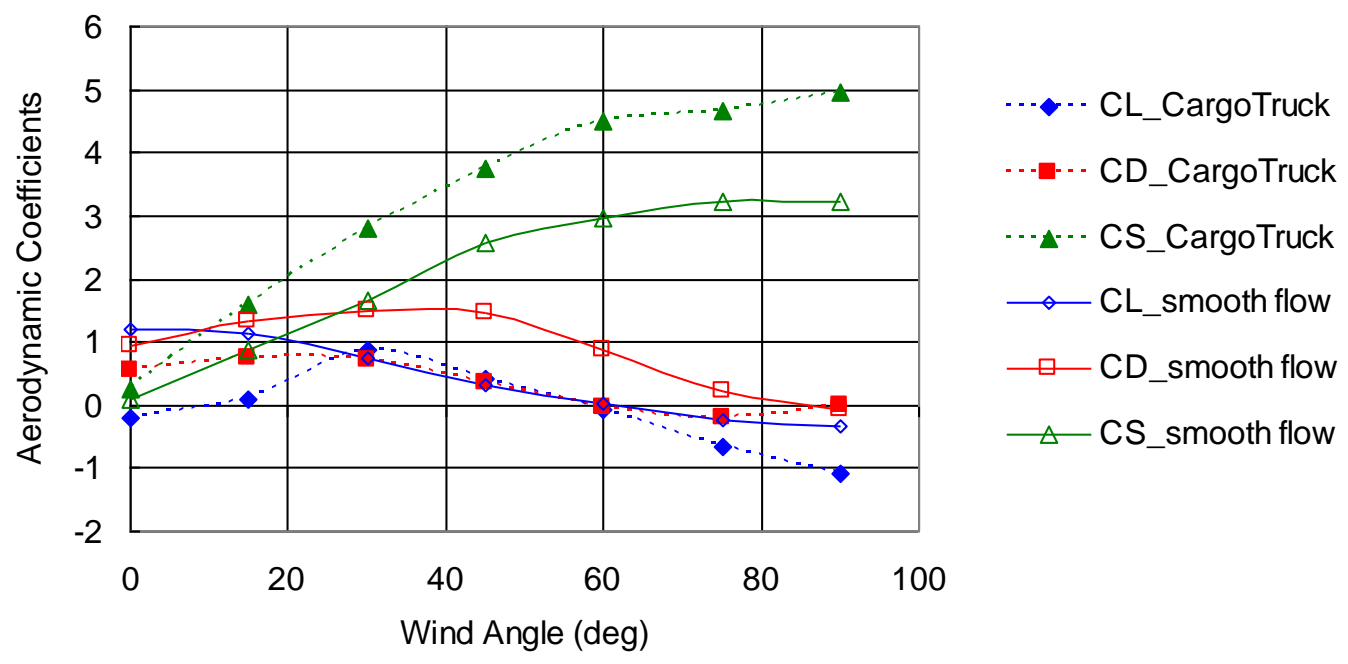

Fig. 16 Comparison of $C_{D}, C_{L}$ and $C_{S}$ for fire truck in smooth flow to tests results on Cargo Truck (Han et al., 2013) 


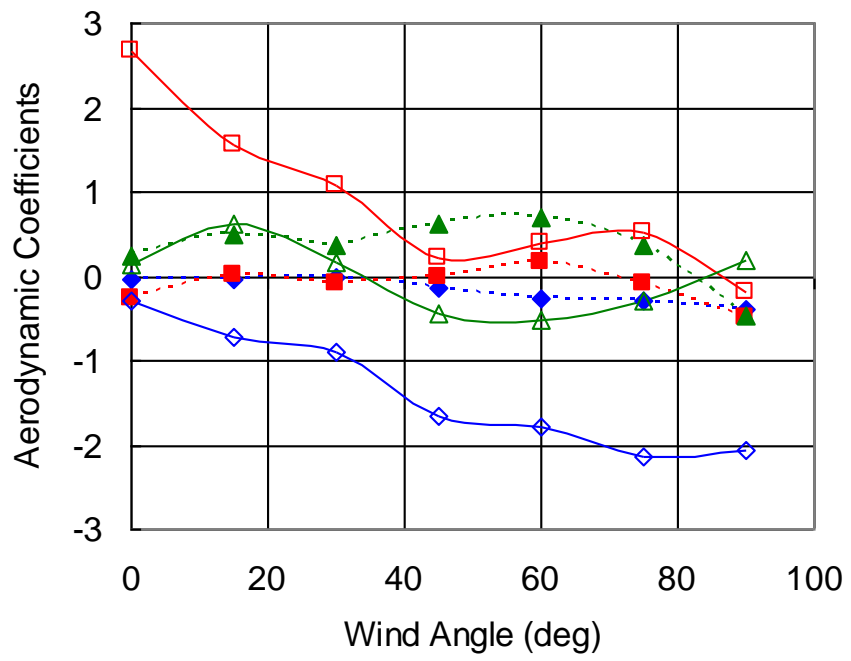

$\cdots$... CR_CargoTruck

-.... CP_CargoTruck

$\cdots$-.... CY_CargoTruck

$\diamond$ CR_smooth flow

$\square$ CP_smooth flow

$\triangle$ CY_smooth flow

Fig. 17 Comparison $C_{R}, C_{P}$ and $C_{Y}$ for fire truck in smooth flow to tests results on Cargo Truck

(Han et al., 2013)

\subsection{Tests in grid turbulence flow}

The tractor-trailer model and the fire truck model were also tested in the turbulent flow conditions. The longitudinal length scale of the turbulence $(5 \mathrm{~cm})$ is about $0.15 \sim 0.2$ the vehicle length. While the actual turbulence scale is usually much larger than the vehicle (2 10 times the vehicle length), it is still advantageous to compare qualitatively the results from the two different flow conditions. These comparisons for tractor-trailer and fire truck are shown in Figs.18 21.

As shown in Figs. 18-21, the absolute values of some coefficients such as $C_{S}, C_{L}$, and $C_{R}$ in the smooth flow are greater than those in the turbulent flow, which illustrates that the smooth flow case gives more conservative results. This trend confirms some previous findings (Baker, 1991). The close match between the two flow conditions for each individual parameter also confirms the repeatability of the current test. The $C_{L}$ for the tractor-trailer in the turbulent flow yields extremely small values. This is possibly due to the instruments problem during the test. 
Tractor-trailer in smooth flow and grid turbulence flow

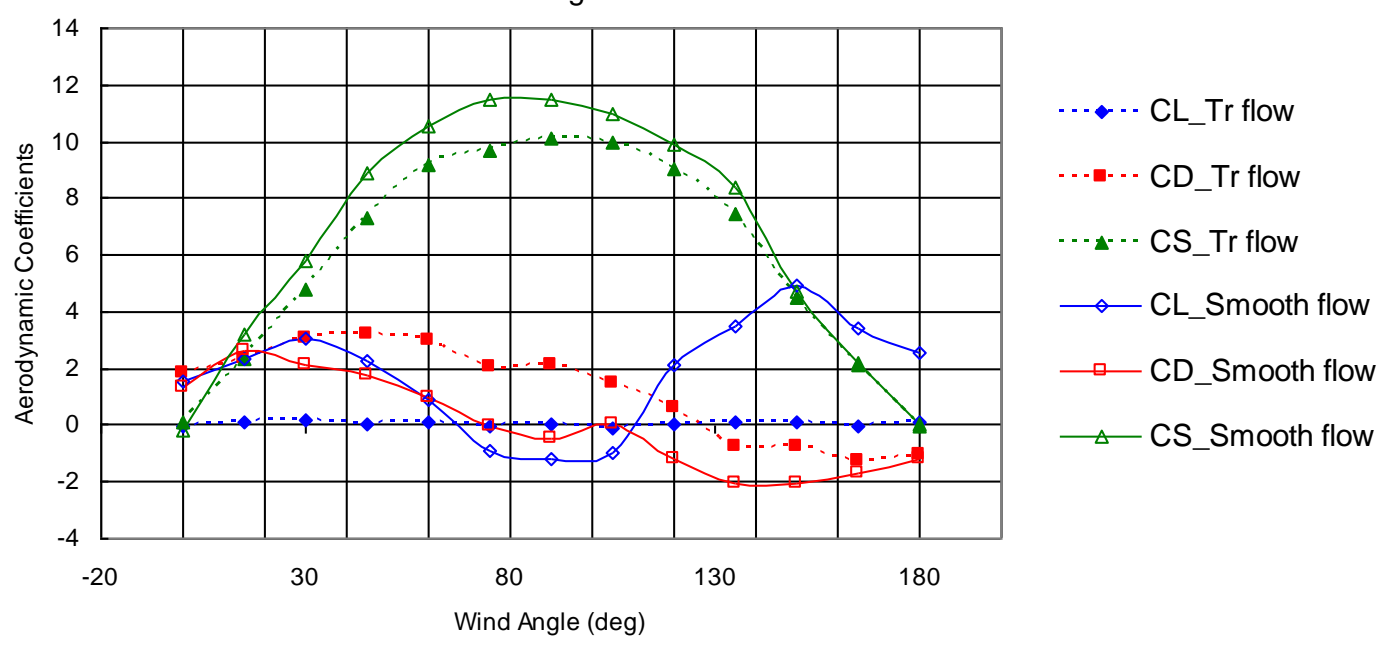

Fig. $18 C_{D}, C_{L}$ and $C_{S}$ for tractor- trailer in smooth and grid turbulence flow

Tractor-trailer in smooth flow and grid turbulence flow

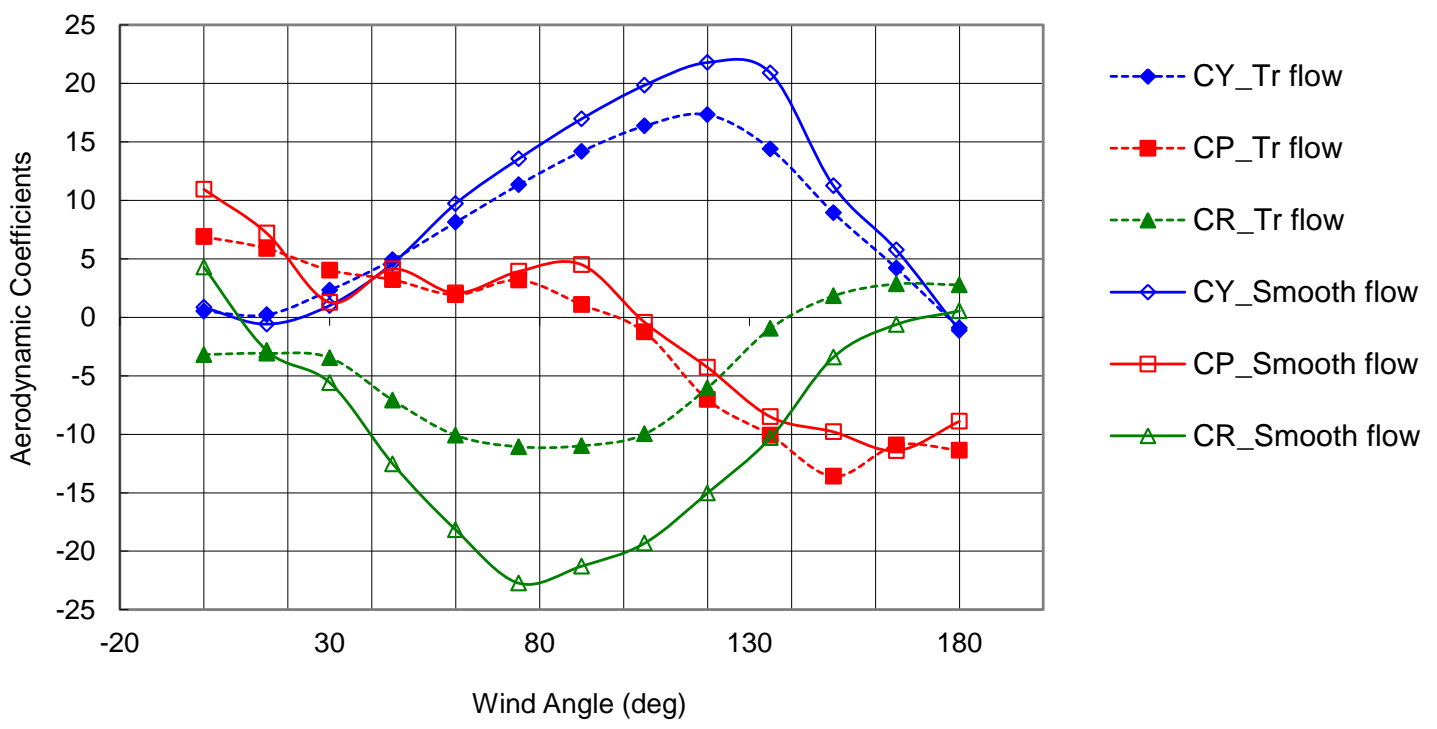

Fig. $19 C_{R}, C_{P}$ and $C_{Y}$ for tractor- trailer in smooth and grid turbulent flow 
Fire truck in smooth flow and grid turbulence flow

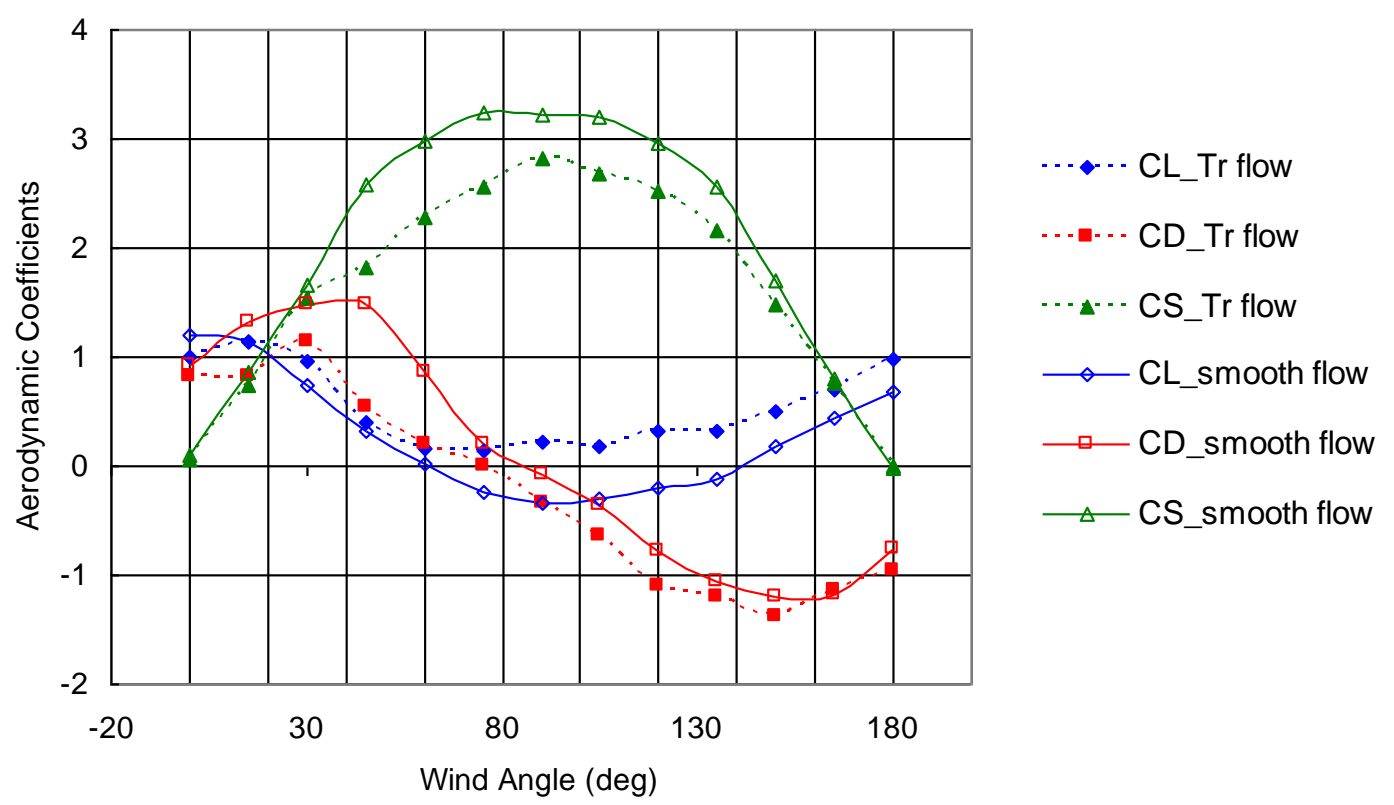

Fig. $20 C_{D}, C_{L}$ and $C_{S}$ for fire truck in smooth and grid turbulent flow

Fire truck in smooth flow and grid turbulence flow

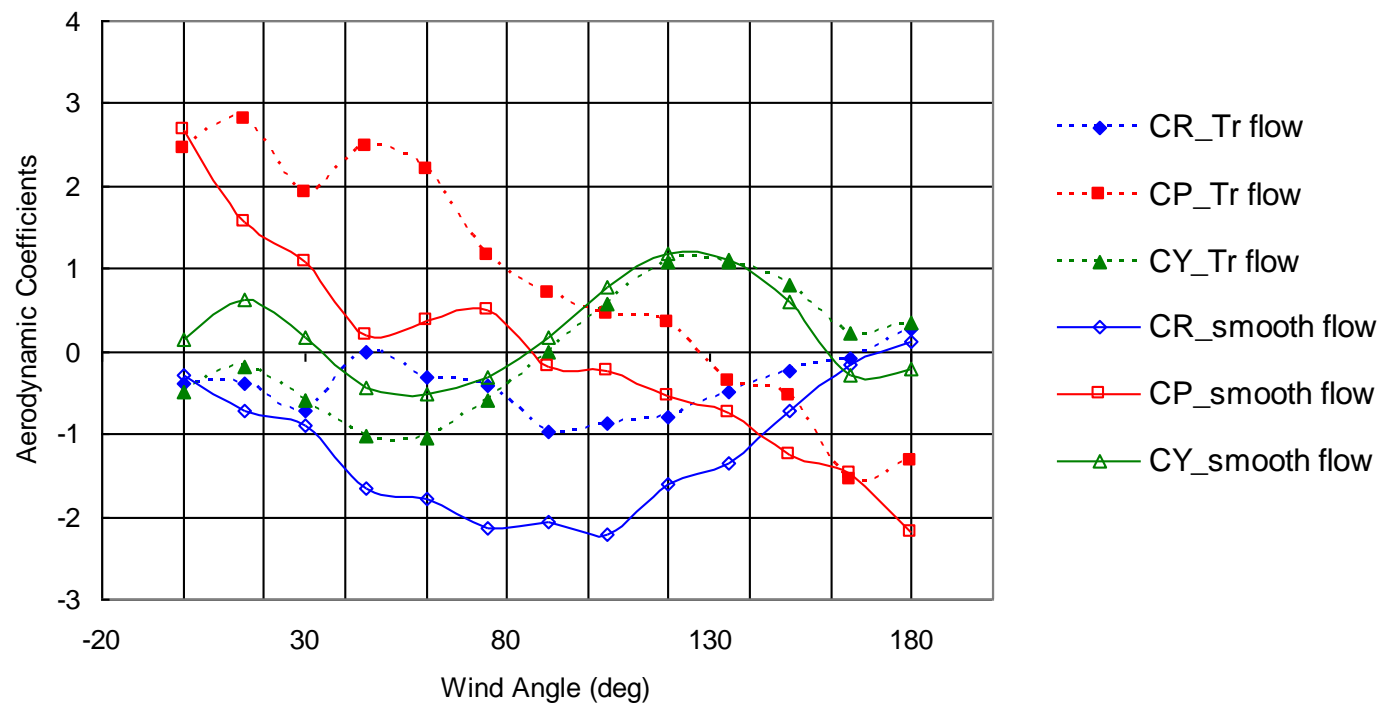

Fig. $21 C_{R}, C_{P}$ and $C_{Y}$ for fire truck in smooth and grid turbulent flow

\subsection{Tests in boundary layer flow}

The boundary layer flow was also adopted in this study. While it is usually argued that the boundary layer should be really thin for a moving vehicle due to the relative velocity of the vehicle to the air underneath, this may not be true for some cases. For instance, when the wind 
approaching angle is 90 180 degree, the flow around the vehicle may not be as simple as a thin boundary layer flow. Therefore, an atmospheric boundary layer is simulated in this study. The fire truck, tractor-trailer, pickup truck, and sedan models were tested in this flow condition. Results for the fire truck are presented in Figs. 22 and 23. Generally speaking, the aerodynamic coefficients have large values for the boundary layer flow condition for most coefficients. After a careful review, the accuracy of $C_{L}$ in the boundary layer flow is in question. It is believed that a negative pressure that was present inside the wind tunnel has caused an artificial lift force on the vehicle models due to the nature of how the boundary layer tests were set up. This problem was only observed in the boundary layer and not the smooth and turbulent flow tests. As can be seen from Figs. 3 and 4, the platform used in the smooth flow and turbulent flow was raised above the test section floor, which eliminated the pressure difference above and below the platform where the model was mounted. However, the mounting disc for the boundary layer flow may experience the pressure difference between the inside and the outside of the wind tunnel, which will be transferred to the final measurement of the lift force eventually. Therefore, the values of $C_{L}$ under the boundary layer flow are considered to be a tainted data set and do not represent an accurate description of lift coefficients.

Fire truck in three different flow conditions

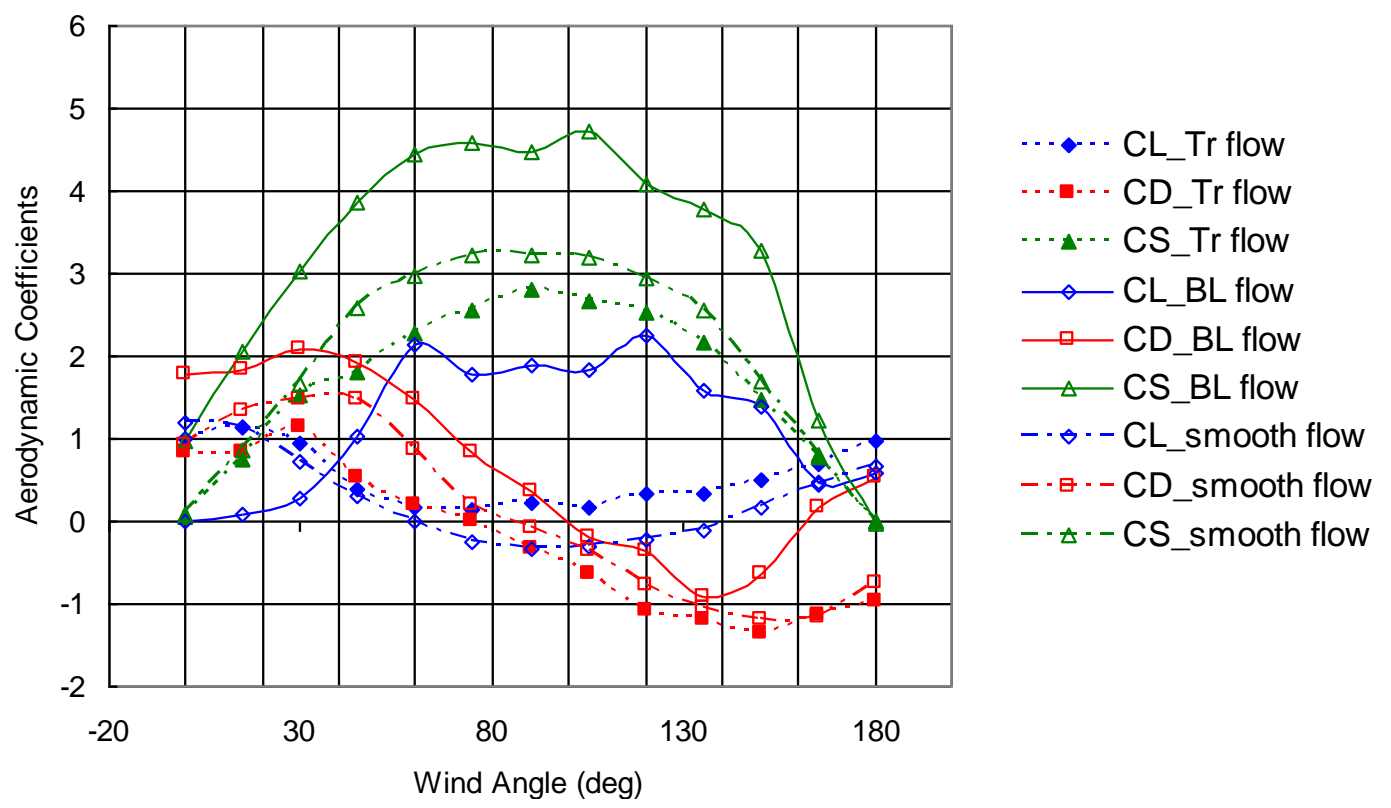

Fig. $22 C_{D}, C_{L}$ and $C_{S}$ for fire truck in different flow conditions 


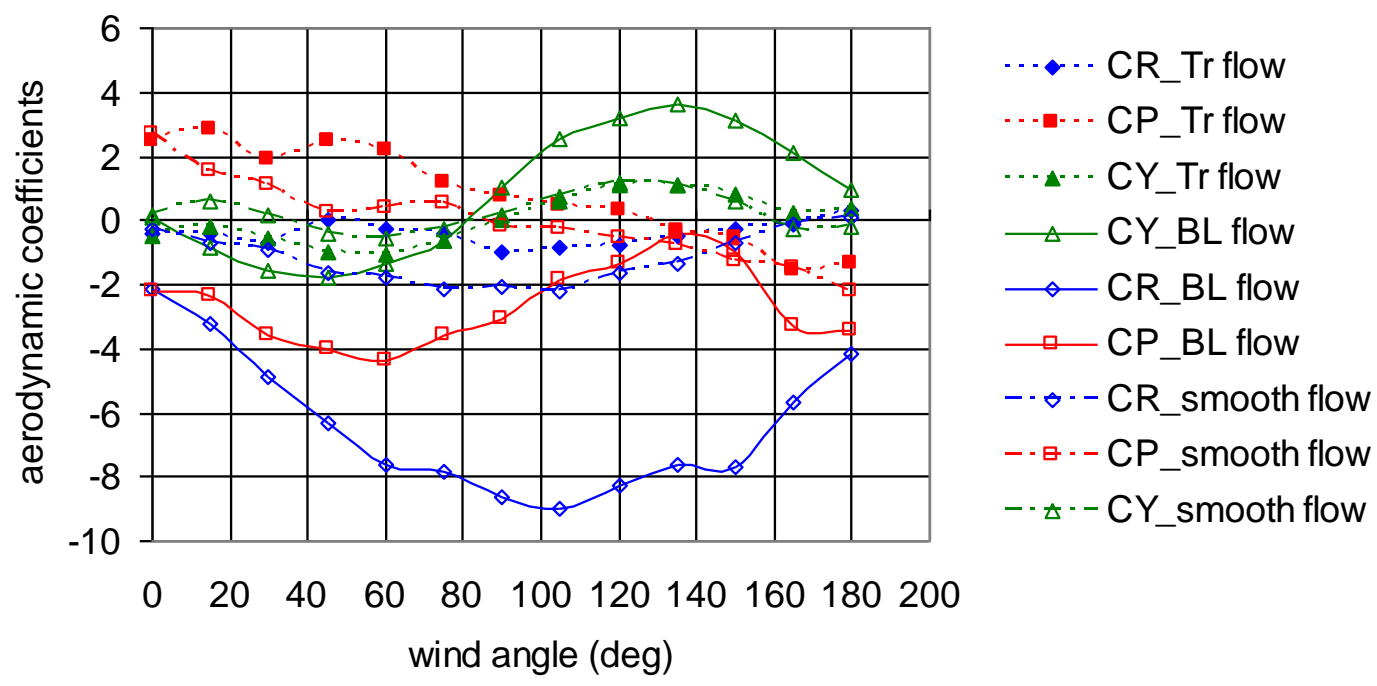

Fig. $23 C_{R}, C_{P}$ and $C_{Y}$ for fire truck in different flow conditions

\section{Conclusions}

In this study, the wind tunnel tests on four types of vehicles under three kinds of flow conditions are described. The results are presented for all these tests and analyzed to interpret the effects of flow conditions on the aerodynamic forces on vehicles. The comparison between the current study and other similar tests are also presented. Some general conclusions can be drawn as follows:

(1) Regardless of the vehicle type, the side force has a very clear trend of sinusoidal type of curves versus the yaw angle. The absolute value of the peak occurs while the wind is blowing perpendicular to the longitudinal direction $\left(\psi=90^{\circ}\right)$, as can be expected. This peak value of the side force coefficient can be further normalized by dividing the side area of the vehicle. It is also observed that the smooth flow usually generates a larger side force coefficient than the turbulent flow. For the tests that were performed in the boundary layer flow, the side force coefficient is even larger than the smooth flow case.

(2) The rolling moment coefficient is closely correlated to the side force coefficient. The trend of the magnitude to the yaw angle is similar to the side force coefficient. The peak absolute value could vary more than ten times depending on the types of the vehicle. This is expected due to the definition of the rolling coefficient, which is purely based on the front projected area. When the vehicle has a large ratio of the side area to the front area, the rolling moment 
coefficient is expected to be a large value. It is also observed that the rolling moment coefficient always tends to be smaller under turbulent flow compared to the smooth flow condition, sometime significantly smaller.

(3) The drag force coefficient generally follows a trend of $A \cdot \sin (2 \psi)$ with values of near zero occurs at $\psi=90$ degree, and the values are nearly symmetrical on magnitude and sign reversed while the yaw angle $\psi$ changing from $\pi / 2$ to 0 and to $\pi$. There is not a general tread regarding the effects of flow conditions. The turbulent flow may generate a larger drag or smaller drag depending on the vehicle geometries.

(4) The lift force coefficient is generally positive while $\psi=0$ or $\pi$, and decreases when the yaw angle change toward to $\pi / 2$. It may change the sign from positive to negative when the yaw angle $\psi$ is in the vicinity of $\pi / 2$.

(5) The pitching moment coefficient generally decreases when the yaw angle is varying from 0 to $\pi$ and it usually changes the sign from positive to negative at around $\psi=\pi / 2$. The effect of the flow condition on the pitching moment coefficient varies for diffident types of vehicles.

(6) The varying trend of the yawing moment coefficient versus the yaw angle is very different for different types of vehicles. It is also observed that the previous studies (Baker, 1987; 1988) reported a very different trend for the yawing moment coefficient compared to the current study.

(7) By inspecting the definition of the moment coefficients, it is obvious that the height of the vehicle center of gravity will affect the results directly. While this height of the center of gravity cannot be easily measured or obtained in the literature, it could be one of the reasons that will cause significant difference when comparing different studies.

\section{Acknowledgements}

This work is partially supported by the Gulf Coast Research Center for Evacuation and Transportation Resiliency (Project No. 600451-00112) and the National Science Foundation (Project No. CMS-0301696). The second author is also supported by the key basic research project (973 project) of P.R. China, under contract No. 2015CB057701 and 2015CB057706.The supports are greatly appreciated. The contents of the paper reflect only the views of the authors. 


\section{References}

Baker C.J. (1986), “A simplified analysis of various types of wind-induced road vehicle accidents", J. Wind Eng. Ind. Aerodyn., 22:69-85.

Baker C.J. (1987), "Measures to control vehicle movement at exposed sites during windy periods", J. Wind Eng. Ind. Aerodyn., 22:151-161.

Baker C.J. (1988), "High sided articulated road vehicles in strong cross winds", J. Wind Eng. Ind. Aerodyn., 31:67-85.

Baker C.J. (1991), "Ground vehicles in high cross winds. 1. Steady aerodynamic forces”, J. Fluids Struct., 5:69-90.

Baker C.J., Reynolds S. (1992), "Wind-induced accidents of road vehicles”, Accid. Anal. Prev., 24(6): 559-575.

Cai C.S., and Chen S.R. (2004), "Frame work of vehicle-bridge-wind dynamic analysis", J. Wind Eng. Ind. Aerodyn., 92:579-607

Chen S.R., and Cai C.S. (2004), “Accident assessment of vehicles on long-span bridges in windy environments", J. Wind Eng. Ind. Aerodyn., 92(12):991-1024.

Coleman, S.A. and Baker, C.J. (1990), "High side road vehicles in cross winds", J. Wind Eng. Ind. Aerod., 36(2), 1383-1392.

Coleman, S.A. and Baker, C.J. (1994), “An experimental study of the aerodynamic behaviour of high sided lorries in cross winds", J. Wind Eng. Ind. Aerod., 53(3), 401-429.

Dorigatti F., Sterling M., Rocchi D., Belloli M., Quinn A.D., Baker C.J., Ozkan E. (2012), “Wind tunnel measurements of crosswind loads on high sided vehicles over long span bridges", J. Wind Eng. Ind. Aerodyn., 107-108:214-224

Garry K. (1984), private communication, Cranfield Institute of Technology.

Guo W.H., Xu Y.L. (2006), "Safety analysis of moving road vehicles on a long bridge under crosswind", J. Eng. Mech., ASCE, 132:438-446.

Han W. S. and Chen A. R. (2007), "Three-dimensional coupling vibration of wind-vehicle-bridge systems", China civil engineering journal, 40(9), 53-58 (In Chinese).

Han Y., Cai C. S., Chen Z. Q. and Hu J. X. (2011), "Aerodynamic characteristics of road vehicles and bridges under cross winds", Proceedings of the 13th International Conference on Wind Engineering, Amsterdam, the Netherlands. 
Han Y., Hu J. X., Cai C. S., Chen Z. Q. and Li C. G. (2013), "Experimental and numerical study of aerodynamic forces on vehicles and bridges", Wind and Structures, 17(2):163-184.

Katz J. (2006), Race Car Aerodynamics: Designing for Speed, 2nd ed., Cambridge: Bentley Publishers.

Li Y. L., Qiang S. Z., Liao H. L. and Xu Y. L. (2005), "Dynamics of wind-rail vehicle-bridge systems", J. Wind Eng. Ind. Aerodyn., 93, 483-507.

Xu Y.L., Guo W.H. (2003), "Dynamic analysis of coupled road vehicle and cable-stayed bridge system under turbulent wind", Eng. Struct., 25:473-486.

Zhu L. D., Li L., Xu Y. L. and Zhu Q. (2012), "Wind tunnel investigations of aerodynamic coefficients of road vehicles on bridge deck", J. Fluids Struct., 30:35-50.. 